\title{
Phanerochaete Chrysosporium Supported Biovalorisation of Grape Pomace for Hyper Reducible Sugar Extraction
}

\author{
J.O. Angadam, S.K.O. Ntwampe* and N. Dlangamandla
}

\begin{abstract}
In the Western Cape, South Africa and other regions globally, grape pomace (GP) is one of the abundant agro-waste from the winery industry. This study reports on the hyper-extraction of fermentable sugars from GP treated with white rot fungi (WRF) Phanerochaete chrysosporium BKMF 1767 to facilitate improved biovalorisation for total reducing sugars (TRS) extraction. TRS were quantified using the 3,5-dinitrosalicylic acid (DNS) reagent method. The free readily dissolvable sugars from the GP recorded for the bio-treated (BT) samples was $206.39 \pm 0.06 \mathrm{mg} / \mathrm{L}$ and for the untreated (UT) samples was $271.05 \pm 0.02 \mathrm{mg} / \mathrm{L}$. Overall, the TRS yield for the Bio-treated (BT) and untreated (UT) samples was recorded as $205.68 \pm 0.09$ and $380.93 \pm 0.14 \mathrm{mg} / \mathrm{L}$, respectively, using hot water pretreatment (HWP) with $2266.00 \pm 0.73$ (BT) and 2850.68 $\pm 0.31 \mathrm{mg} / \mathrm{L}$ (UT), respectively, for dilute acid pretreatment (DAP); with $2068.49 \pm 6.02$ (BT) and $2969.61 \pm 8.054 \mathrm{mg} / \mathrm{L}$ (UT) respectively, using the cellulase pretreatment $(\mathrm{CP})$ method. Using the HWP as a reference, the relative increases imparted by the bio-treatment was higher (51\%) for DAP and low (33\%) for CP.
\end{abstract}

Keywords-Agro-waste, Grape pomace, Phanerochaete chrysosporium, Total reducing sugars.

\section{INTRODUCTION}

There are bountiful, inexpensive and renewable lignocellulosic biomass being landfilled continuously by the winery industry. The winery and juicing industries are among the profitable and substantial agro-economic operations worldwide, processing a variety of grape berries. After the

Manuscript received August 24, 2018. The authors acknowledge funding from the Cape Peninsula University of Technology (CPUT) and the National Research Foundation (NRF) of South Africa.

J.O. Angadam is with the Bioresource Engineering Research Group (BioERG), Faculty of Applied Science, Department of Biotechnology, Cape Peninsula University of Technology.

*S.K.O. Ntwampe, corresponding author, is the founder of Bioresource Engineering Research Group (BioERG), Faculty of Applied Science, Department of Biotechnology, Cape Peninsula University of Technology, P.O. Box 652,Cape Town, 8000, South Africa.

N. Dlangamandla is with the Bioresource Engineering Research Group (BioERG), Faculty of Applied Science, Department of Biotechnology, Cape Peninsula University of Technology. extraction of the juice from grapes, approximately $20 \%$ end-up as grape pomace (GP) containing skins, seeds, and stems-major components of holocellulose, which are landfilled, culminating in growing environmental pollution concerns [1]. Instead of land filling, this GP can be used as animal feed or as a source of fermentable sugars $[2,3]$. If the GP is not treated or handled accordingly, it can result in deleterious environmental pollution challenges including release of extracts which will seep into ground-water bodies; this being among the challenges identified [4]. Thus, the repurposing of GP, will serve as a means to remove waste containing phenolics and other potential toxicants from the environment and also as an alternative nutrient source for the production of value-added products [5].

GP is composed mostly of holocellulosic material which is categorized as a key source of fermentable sugars for the production of value-added products [6]; albeit, it is challenging to degrade because of the presence of lignin [7]. The effect of milling and biological pre-treatment (bio-treatment) on fermentable sugar extraction from such GP has not been studied effectively. Some pretreatment methods, can be used for fermentable sugar extraction, with hot water, dilute sulphuric acid and cellulase pretreatment methods being preferred [8-11]. Recent studies have shown that, pre-treatment techniques used to pre-treat lignocellulosic biomass encompassing agro-waste, are making emphases on the reduced pre-treatment time, exploiting the removal of fermentable sugars while reducing energy intensity usage, including the utilization of environmentally benign processes by eliminating the use of chemicals and at reduced operating cost [12]. These processes can be utilized either as independent or as combined processes [13-19].

This research presents the effect of bio-pretreatment using Phanerochaete chrysosporium BKMF1767 on different commonly used pretreatments methods for hyper-extraction of TRS from GP, since they are deemed to be easily fermentable. 


\section{MATERIALS AND METHODS}

A. Collection and Preparation: Grape Pomace as a Holocellulosic Biomass Feedstock

GP (Vitis vinifera waste), was collected from ARC's Nietvoorbij experimental cellar farm (with permission), Stellenbosch, Cape Town (Western Cape, South Africa). The GP was immediately stored in a plastic bag and placed on ice prior to transportation, and subsequent to storage at $-20^{\circ} \mathrm{C}$. The samples were thawed prior to drying in an oven at $80^{\circ} \mathrm{C}$ for 3 days. The samples were milled to a powder using a ball mill to $>45 \mu \mathrm{m}<100 \mu \mathrm{m}$ without a pre-washing step. A mass $(10 \mathrm{~g})$ of the milled sample was weighed and mixed with Phanerochaete chrysosporium BKMF1767 inoculum (10\% v/v) grown in agar plates as described and highlighted in Ntwampe [20] and placed in an incubator for 7days. Mass (2g) of the bio-treated and an untreated samples, were weighed and transferred into Schott bottles. A volume $(200 \mathrm{~mL})$ of sterile distilled water was added to the samples for slurrification and readily dissolvable sugars were measured after $6 \mathrm{~h}$. This was followed by HWP.

\section{B. Hot Water Pretreatment (HWP)}

The samples were then autoclaved at $121^{\circ} \mathrm{C}$ for $15 \mathrm{mins}$. The samples were cooled and samples $(6 \mathrm{~mL})$ from a homogenous mixture were centrifuged at $4000 \mathrm{xg}$ for $5 \mathrm{mins}$. A volume sample $(1 \mathrm{~mL})$ was then added to distilled water $(9 \mathrm{~mL})$ for dilution. The essay mixture was composed of equivalent aliquots of the diluted sample and DNS $(1,5 \mathrm{~mL})$ in sterile test tubes, with a $7305 \mathrm{UV} / \mathrm{Vis}$ spectrometer (Cole-Parmer, UK) being used to measure the absorbance at $575 \mathrm{~nm}$; hence, TRS quantification.

\section{Dilute Acid Pretreatment (DAP)}

DAP commenced immediately after HWP. A volume $(1 \mathrm{~mL})$ of $1 \%(\mathrm{v} / \mathrm{v})$ dilute sulphuric acid was added to the Schott bottles containing the samples. It was heated for $30 \mathrm{mins}$ at $121^{\circ} \mathrm{C}$. The samples were cooled subsequent to centrifuging at $4000 \mathrm{xg}$ for 5mins. A volume of samples $(1 \mathrm{~mL})$ was then added to distilled water $(9 \mathrm{~mL})$ for dilution. Thereafter, TRS was quantified.

\section{Cellulase Pretreatment ( $C P$ )}

After the DAP process, CP commenced. The $\mathrm{pH}$ of the samples was adjusted to 4.5 using sodium acetate buffer $(\mathrm{pH}=5.6)$. A volume $600 \mathrm{uL} / \mathrm{g}$ waste of commercial cellulase $(24.67 \mathrm{U} / \mathrm{mL})$ was pipetted into the Schott bottles containing the samples. It was heated to $55^{\circ} \mathrm{C}$ for $72 \mathrm{~h}$. Thereafter, TRS was quantified and some of the filtrate was stored at $-20^{\circ} \mathrm{C}$ for future use.

\section{E. Quantification of Total Reducible Sugars (TRS)}

The TRS that were extracted during the pretreatment of the GP was measured using a DNS based method, with the assay mixture being composed of DNS (10g), phenol (2g), sodium sulphite $(0.5 \mathrm{~g})$ and sodium hydroxide $(10 \mathrm{~g})$, made-up to $1000 \mathrm{~mL}$ using sterile distilled water [21]. Aliquots of the diluted sample and DNS $(1,5 \mathrm{~mL})$ was transferred into sterile test tubes and heated in a water bath for $10 \mathrm{mins}$ at $90^{\circ} \mathrm{C}$, subsequent to cooling to ambient temperature followed by the addition of a $40 \%(\mathrm{v} / \mathrm{v})$ sodium potassium tartrate $(0.5 \mathrm{~mL})$ solution into test tubes for TRS concentration analyses using a spectrophotometer $(575 \mathrm{~nm})$. Different glucose concentration standards $(0-1000 \mathrm{mg} / \mathrm{L})$ were used to produce an appropriate calibration curve. The control was distilled water and DNS solution, without the diluted samples. Figure 1A to 1C, highlight the results of TRS concentration obtained using different pre-treatment methods.

\section{DATA HANDLING}

\section{A. Effectiveness of P. Chrysosporium Bio-treatment on TRS Extraction using Mild Acid and Cellulases}

In order to assess the effectiveness of biologically pre-treating the GP, comparative absolute relative increases between mild acid and cellulase pre-treated GP was assessed using the HWP processes as a reference, as it had a minor or insignificant contribution to the TRS extracted from the GP. This was computed using Eq.1:

$\%$ Relative Increase $=\left(\frac{\Delta T A S_{C P}}{\Delta T A S_{D A P}}-1\right) \times 100$

Whereby $\triangle T R S$ for both cellulases $\left(\triangle T R S_{C P}\right)$ and mild acid $\left(\triangle T R S_{D A P}\right)$ pretreatment can be estimated using Eq. 2:

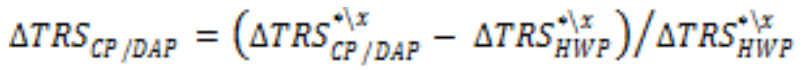

With $* / x$ being $\triangle T R S$ for $P$. chrysosporium treated (*) or untreated GP $(x)$. Standard deviation from a triplicate set of experiments was used in this study to account for variations in datasets.

\section{RESUlts AND Discussion}

\section{A. Selection of Agro-waste}

Studies have identified holocellulosic materials as one of the major source of fermentable sugars for the production of bio-ethanol and other value-added products [6]. GP is a regionally available and inexpensive feedstock in the Western Cape; albeit, its availability is seasonal. Furthermore, although GP can be used to produce fermentable sugars, it does contain some inhibitory compounds such as $\rho$-coumaric, ferulic, acetic, glucuronic acids including furfural and phenolics, which are released during pre-treatment processes [22]. Alternatively, cellulases can reduce some of these fermentation inhibiting 
by-products, while catalyzing fermentable sugar extraction from different agro-waste [23].

\section{B. Total Readily Dissolvable Sugars}

The freely dissolvable sugar obtained during GP slurrification for the untreated samples was $271.05 \pm 0.02 \mathrm{mg} / \mathrm{L}$ and $206.39 \pm 0.06 \mathrm{mg} / \mathrm{L}$ for the $P$. chrysosporium treated samples, respectively. This revealed that $P$. chrysosporium used some of the freely available sugars present in the slurrified samples thus the reduced quantity of the TRS at the initiation of the experiments with differentiation being determined to be miniscule in comparison to the TRS present in the untreated samples.

\section{Hot Water Pretreatment (HWP)}

This is a commonly used pretreatment method, with its function being to delignify/or loosen the holocellulose in order, to improve its penetrability during hydrolysis. Thermal methods broadens the penetrable and vulnerable surface area of densely, lignified biomass, for improved accessibility by hydrolytic enzymes [24, 25]. For HWP, the TRS concentration for the untreated sample was $380.93 \pm 0.14 \mathrm{mg} / \mathrm{L}$, with that observed for bio-treated samples being $205.68 \pm 0.09 \mathrm{mg} / \mathrm{L}$. Although this pretreatment method can be classified as advantageous due to non-use of chemicals including independence of the agro-waste particle size, it is however, energy intensive with a higher water requirement than some pretreatment methods and it produces some toxicants such as furfural and phenolics which can sour downstream processes [26, 27].

\section{Dilute Acid Pretreatment (DAP)}

One of the effective pretreatment methods used to delignify and solubilised agro-waste components to fermentable sugars is the dilute sulphuric acid pretreatment method. Its function is to solubilize hemicellulose to monosaccharides. At a higher temperature, sulphuric acid will also degrade xylose and some waste components into inhibitory compounds such as soluble lignin [8, 10, 22, 27, 28]. The yield for TRS was $2850.68 \pm 0.31$ $\mathrm{mg} / \mathrm{L}$ for the untreated sample, with $2266.00 \pm 0.73 \mathrm{mg} / \mathrm{L}$ being the concentration of TRS for the bio-treated samples. The acid pretreatment in combination with bio-treated samples released a higher concentration of fermentable sugars as compared to the HWP, probably due to the loosened hemicellulose and cellulose (structure) which culminated in the ease of the holocellulose decoupling. Although acid pretreatment is effective and produces a high yield of fermentable sugars, it also has some limitations which include corrosiveness and the degradation of xylose and glucose units at high temperatures $[24,27]$.

\section{E. Cellulase Pretreatment (CP)}

Cellulases are a cocktail of enzymes used to hydrolyze, hemicellulose and cellulose, and are constituted by endoglucanases, cellobiohydrolases (exoglucanases), and $\beta$-glucosidases [6]. By using cellulases, the delignified biomass structure, can be easily converted to disaccharides and further into fermentable monosaccharides. As there is a need for environmental benign, efficient, and inexpensive processes, cellulase for agro-waste pretreatment is deemed suitable. Numerous pretreatment practices are required to alter the physical and chemical composition of the lignocellulosic biomass, with enhanced hydrolysis rates being observed for biomass pre-treated with dilute acid prior to cellulase pre-treatment [29]; although, this can culminate into residual toxicants when compared to sole cellulase pre-treatment which produces less harmful by-products. By pretreating the agrowaste with hot water and dilute acid can facilitate efficient cellulase treatment to slacken hemicellulose and celluloses for efficient debonding by the cellulases. After hot water and acid pretreatment, cellulase pretreatment effectively produced $2969.61 \pm 8.05 \mathrm{mg} / \mathrm{L}$ (untreated samples) and 2068.49 \pm 6.02 $\mathrm{mg} / \mathrm{L}$ TRS for the bio-treated samples. The cumulative TRS obtainable is represented by Eq. 3 (untreated) and Eq. 4 (bio-treated).

$\Delta T R S_{T}=6201.22 \pm 8.50 \mathrm{mg} / \mathrm{L}$

$\Delta T R S_{\mathrm{T}}=4540.17 \pm 6.84 \mathrm{mg} / \mathrm{L}$

F. Relative Increases of TRS by Bio-pretreatment

TABLE I: HIGHER RELATIVE INCREASES OF TRS BY BIO-TREATMENT

\begin{tabular}{lccc}
\hline $\begin{array}{l}\text { Pre-treatment } \\
\text { methods }\end{array}$ & $\begin{array}{c}\text { Untreated } \\
(\%)\end{array}$ & $\begin{array}{c}\text { Treated } \\
(\%)\end{array}$ & $\begin{array}{c}\text { Related } \\
\text { Increases }(\%)\end{array}$ \\
\hline Mild acid & 650 & 980 & 51 \\
Cellulase & 682 & 886 & 33 \\
\hline \hline
\end{tabular}

Table I, highlights relative increases of TRS. Relative increases are the difference in the change between the different pre-treatment processes for the untreated samples and bio-treated samples, using HWP as a reference. 


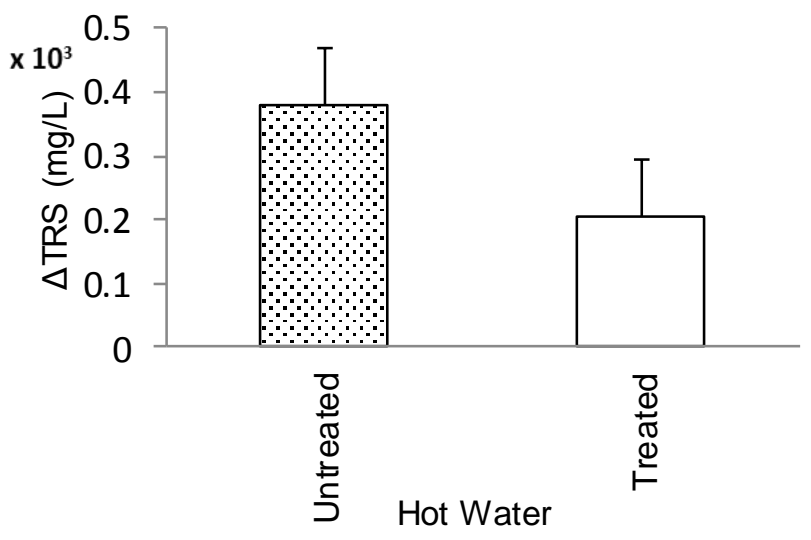

$\mathbf{A}$

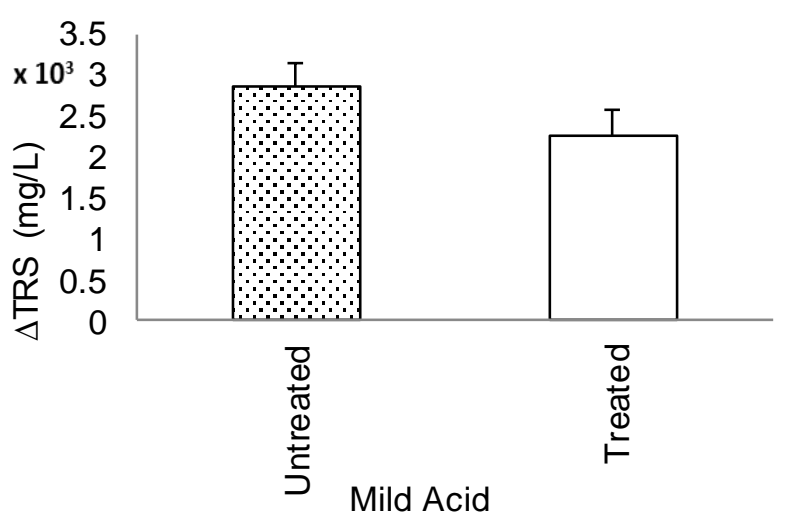

B

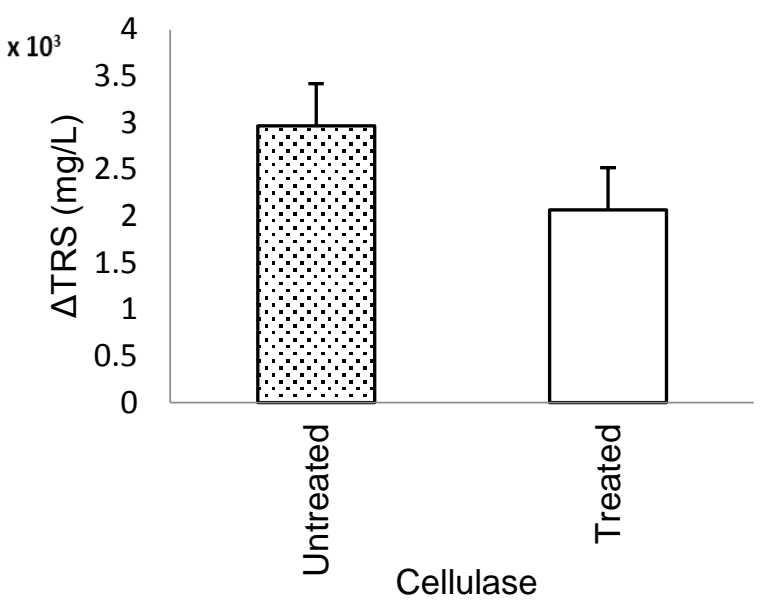

C

Fig 1: TRS results recorded for hot water (A), mild acid (B) and cellulase (C) pretreatments for the untreated and P. chrysosporium treated GP.

Overall, the relative increases for the bio-treated samples were higher than those of the untreated samples. This can be attributed to the fact that, the WRF helped in delignifying the samples; hence, making it easy for the pre-treatment procedures to perform optimally.

\section{CONCLUSION}

From the results obtained in this study, the cellulase pretreatment was determine to be an effective technique for the extraction of fermentable sugars from GP. This was seen in the TRS produced as $2969.61 \pm 8.05 \mathrm{mg} / \mathrm{L}$ recorded for the untreated samples and $2068.49 \pm 6.02 \mathrm{mg} / \mathrm{L}$ recorded for the Phanerochaete chrysosporium treated samples. Overall, cumulative TRS was $6201.22 \pm 8.50 \mathrm{mg} / \mathrm{L}$ for untreated samples and $4540.17 \pm 6.84 \mathrm{mg} / \mathrm{L}$ for treated sample. From the results of this research, it can be deduced that Phanerochaete chrysosporium used some of the readily available sugars in the samples for growth purposes. Although it contributed to higher relative increases for TRS extraction.

\section{REFERENCES}

[1] R. Gama, "A Lignocellulolytic Enzyme System for Fruit Waste Degradation: Commercial Enzyme Mixture Synergy and Bioreactor Design," Rhodes University, 2013.

[2] D. R. Figueira, "Valorization of agro-industrial waste through chemical and microbiological approaches," 2017.

[3] L. J. Korkie, B. J. H. Janse, and M. Viljoen-Bloom, "Utilising grape pomace for ethanol production," 2017, vol. 23, no. 1, pp. 6, 2017.

[4] R. Devesa-Rey, X. Vecino, J. Varela-Alende, M. Barral, J. Cruz, and A. Moldes, "Valorization of winery waste vs. the costs of not recycling," Waste Management, vol. 31, no. 11, pp. 2327-2335, 2011. https://doi.org/10.1016/j.wasman.2011.06.001

[5] Y. Zheng, J. Zhao, F. Xu, and Y. Li, "Pretreatment of lignocellulosic biomass for enhanced biogas production," Progress in Energy and Combustion Science, vol. 42, pp. 35-53, 2014. https://doi.org/10.1016/j.pecs.2014.01.001

[6] R. Kumar, S. Singh, and O. V. Singh, "Bioconversion of lignocellulosic biomass: biochemical and molecular perspectives," Journal of Industrial Microbiology and Biotechnology, vol. 35, no. 5, pp. 377-391, 2008. https://doi.org/10.1007/s10295-008-0327-8

[7] L. Bhatia, S. Johri, and R. Ahmad, "An economic and ecological perspective of ethanol production from renewable agro waste: a review," AMB Express, vol. 2, no. 1, pp. 65-83, 2012. https://doi.org/10.1186/2191-0855-2-65

[8] P. Alvira, E. Tomás-Pejó, M. Ballesteros, and M. J. Negro, "Pretreatment technologies for an efficient bioethanol production process based on enzymatic hydrolysis: A review," Bioresource Technology, vol. 101, no. 13, pp. 4851-4861, 2010. https://doi.org/10.1016/j.biortech.2009.11.093

[9] J. Gao, L. Chen, K. Yuan, H. Huang, and Z. Yan, "Ionic liquid pretreatment to enhance the anaerobic digestion of lignocellulosic biomass," Bioresource Technology, vol. 150, pp. 352-358, 2013. https://doi.org/10.1016/j.biortech.2013.10.026

[10] M. Idrees, A. Adnan, S. Sheikh, and F. A. Qureshic, "Optimization of dilute acid pretreatment of water hyacinth biomass for enzymatic hydrolysis and ethanol production," EXCLI Journal, vol. 12:, pp. 30-40, 2013.

[11] M. Shafiei, R. Kumar, and K. Karimi, "Pretreatment of Lignocellulosic Biomass," Lignocellulose-Based Bioproducts, K. Karimi, ed., pp. 85-154, Cham: Springer International Publishing, 2015. 
https://doi.org/10.1007/978-3-319-14033-9_3

[12] L. S. Hyun, D. T. V., L. R. J., and D. J. S., "Ionic liquid-mediated selective extraction of lignin from wood leading to enhanced enzymatic cellulose hydrolysis," Biotechnology and Bioengineering, vol. 102, no. 5, pp. 1368-1376, 2009. https://doi.org/10.1002/bit.22179

[13] C.-L. Cheng, P.-Y. Che, B.-Y. Chen, W.-J. Lee, C.-Y. Lin, and J.-S. Chang, "Biobutanol production from agricultural waste by an acclimated mixed bacterial microflora," Applied Energy, vol. 100, pp. 3-9, 2012. https://doi.org/10.1016/j.apenergy.2012.05.042

[14] D. Chiaramonti, M. Prussi, S. Ferrero, L. Oriani, P. Ottonello, P. Torre, and F. Cherchi, "Review of pretreatment processes for lignocellulosic ethanol production, and development of an innovative method," Biomass and Bioenergy, vol. 46, pp. 25-35, 2012/11/01/, 2012.

[15] A. K. Kumar, B. S. Parikh, and M. Pravakar, "Natural deep eutectic solvent mediated pretreatment of rice straw: bioanalytical characterization of lignin extract and enzymatic hydrolysis of pretreated biomass residue," Environmental Science and Pollution Research, vol. 23, no. 10, pp. 9265-9275, 2016. https://doi.org/10.1007/s11356-015-4780-4

[16] S. H. Lee, T. V. Doherty, R. J. Linhardt, and J. S. Dordick, "Ionic liquid-mediated selective extraction of lignin from wood leading to enhanced enzymatic cellulose hydrolysis," Biotechnology and Bioengineering, vol. 102, no. 5, pp. 1368-1376, 2009. https://doi.org/10.1002/bit.22179

[17] N. Narayanaswamy, P. Dheeran, S. Verma, and S. Kumar, "Biological pretreatment of lignocellulosic biomass for enzymatic saccharification," Pretreatment Techniques for Biofuels and Biorefineries, Z. Fang, ed., pp. 3-34, Berlin, Heidelberg: Springer Berlin Heidelberg, 2013. https://doi.org/10.1007/978-3-642-32735-3_1

[18] A. Procentese, F. Raganati, G. Olivieri, M. Elena Russo, and A. Marzocchella, "Pre-treatment and enzymatic hydrolysis of lettuce residues as feedstock for bio-butanol production," Biomass and Bioenergy, vol. 96, pp. 172-179, 2017. https://doi.org/10.1016/j.biombioe.2016.11.015

[19] K. Rajan, and D. J. Carrier, "Effect of dilute acid pretreatment conditions and washing on the production of inhibitors and on recovery of sugars during wheat straw enzymatic hydrolysis," Biomass and Bioenergy, vol. 62, pp. 222-227, 2014. https://doi.org/10.1016/j.biombioe.2014.01.013

[20] S. Ntwampe, "Multicapillary Membrane Design," MTech thesis. Cape Peninsula University of Technology, 2005.

[21] G. L. Miller, "Use of dinitrosalicylic acid reagent for determination of reducing sugar," Analytical Chemistry, vol. 31, no. 3 , pp. 426-428, 1959 . https://doi.org/10.1021/ac60147a030

[22] L. J. Jönsson, and C. Martín, "Pretreatment of lignocellulose: Formation of inhibitory by-products and strategies for minimizing their effects," Bioresource Technology, vol. 199, pp. 103-112, 2016. https://doi.org/10.1016/j.biortech.2015.10.009

[23] R. R. Singhania, A. K. Patel, R. K. Sukumaran, C. Larroche, and A. Pandey, "Role and significance of beta-glucosidases in the hydrolysis of cellulose for bioethanol production," Bioresource Technology, vol. 127, pp. 500-507, 2013. https://doi.org/10.1016/j.biortech.2012.09.012

[24] C. Selvaraj, and P. T. Vasan, "Ethanol tolerant Zymomonas mobilis for bioethanol production from vegetable wastes," International Journal of Academic Research and Development, vol. 2, no. 5, pp. 191-196, 2017.
[25] J. M. Taherzadeh, and K. Karimi, "Pretreatment of lignocellulosic wastes to improve ethanol and biogas production: A Review," International Journal of Molecular Sciences, vol. 9, no. $9,2008$. https://doi.org/10.3390/ijms9091621

[26] A. T. W. M. Hendriks, and G. Zeeman, "Pretreatments to enhance the digestibility of lignocellulosic biomass," Bioresource Technology, vol. 100, no. 1, pp. 10-18, 2009. https://doi.org/10.1016/j.biortech.2008.05.027

[27] D. P. Maurya, A. Singla, and S. Negi, "An overview of key pretreatment processes for biological conversion of lignocellulosic biomass to bioethanol," 3 Biotech, vol. 5, no. 5, pp. 597-609, 2015.

[28] A. M. J. Kootstra, H. H. Beeftink, E. L. Scott, and J. P. M. Sanders, "Comparison of dilute mineral and organic acid pretreatment for enzymatic hydrolysis of wheat straw," Biochemical Engineering Journal, vol. 46, no. 2, pp. 126-131, 2009. https://doi.org/10.1016/j.bej.2009.04.020

[29] J. Zeng, D. Singh, and S. Chen, "Biological pretreatment of wheat straw by Phanerochaete chrysosporium supplemented with inorganic salts," Bioresource Technology, vol. 102, no. 3, pp. 3206-3214, 2011. https://doi.org/10.1016/j.biortech.2010.11.008

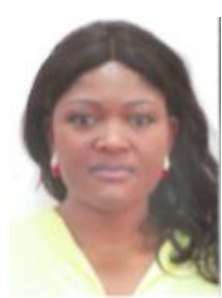

J.O. Angadam was born in Akutah Andek Cameroon in 1989, obtaining Baccalaureus Technologiae in Biomedical Technology (Biotechnology) in 2016, and a National Diploma in Biotechnology in 2015, at the Cape Peninsula University of Technology, Cape Town, South Africa. She obtained her Advanced Level Certificate in Natural Sciences (Matric) in 2007 in Cameroon at the Protestant College Bali, Bali Cameroon with her First School Leaving Certificate (2000) being obtained from the Presbyterian School Andek Cameroon. Currently, she performs duties as an office co-ordinator for BioERG, while being an assistant laboratory technician, teaching assistant and tutor. Ms Angadam, has presented the following articles at an international conference: E.A Akinpelu, S.K.O. Ntwampe J.O. Angadam (2018). Diversity and performance of sulphate reducing bacteria in acid mine drainage remediation systems" has been submitted at WaterEnergyNEXUS conference. 